\title{
ACUTE LYMPHOBLASTIC LEUKEMIA AND SEIZURES
}

The incidence, timing, etiologies, and recurrence rate of seizures among 127 pediatric patients with acute lymphoblastic leukemia (ALL) were determined at the Schneider Children's Hospital, and the Long Island Jewish Medical Center, New York. Of 17 patients (13\%) who developed one or more seizures, 16 had seizures during antileukemic treatment, almost always related to intrathecal methotrexate or subcutaneous L-asparaginase. The long-term recurrence risk of seizures was low, occurring only in 2 patients (12\%) who had static encephalopathy and neurologic deficits. Chronic antiepileptic drug therapy was restricted to patients with recurrent seizures and structural cerebral lesions. (Maytal J et al. Prognosis and treatment of seizures in children with acute lymphoblastic leukemia. Epilepsia August 1995;36:831-836). (Reprints: Dr J Maytal, Division of Pediatric Neurology, Schneider Children's Hospital, New Hyde Park, NY 11042).

COMMENT. Seizures occurring in children with ALL in this study were related to side-effects of chemotherapy. None had seizures secondary to CNS leukemic relapse. Phenytoin was the drug of choice for the control of the acute seizures because of its relative lack of behavioral and sedative adverse effects. Carbamazepine and valproate were avoided because of potential bone marrow suppression and the lack of intravenous preparations.

\section{CEREBRAL CORTICAL DYSGENESIS AND EPILEPSY IN ADULTS}

The clinical, EEG and neuroimaging features in 100 adult patients with cerebral cortical dysgenesis (CD) were reviewed at the National Hospital for Neurology and Neurosurgery, St Mary's Hospital, London, and the National Society for Epilepsy, Chalfont St Peter, Gerrards Cross, UK. Patients had medically refractory epilepsy with onset at a median age of 10 years. Only $15 \%$ had a history of status epilepticus. Diagnosis was by neuroimaging in 70 . EEGs were abnormal in $95 \%$. Of 35 patients treated by surgery, 15 were completely seizure-free. Demonstration of subtle forms of CD by MRI lessen the incidence of cryptogenic epilepsy in adult patients. (Raymond AA et al. Abnormalities of gyration, heterotopias, tuberous sclerosis, focal cortical dysplasia, microdysgenesis, dysembryoplastic neuroepithelial tumour and dysgenesis of the archicortex in epilepsy. Clinical, EEG and neuroimaging features in 100 adult patients. Brain June 1995;118:629-660). (Respond: Dr DR Fish, Department of Clinical Neurophysiology, National Hospital for Neurology and Neurosurgery, Queen Square, London WC1N 3BG, UK).

COMMENT. The heterogeneity of abnormalities associated with CD in adults with epilepsy, as listed in the title of this article, was associated with varied clinical, EEG and MRI features. Compared to children with epilepsy and $C D$, these adult patients had a relatively low frequency of delayed milestones (12\%), mental retardation (11\%) and neurologic deficits (17\%).

\section{MENINGOMYELOCELE AND EPILEPSY}

The prevalence of seizures and epilepsy and the occurrence of other brain malformations or structural abnormalities were examined in 81 children with meningomyelocele followed at the multidisciplinary Children's Clinics 
for Rehabilitative Services, University of Arizona Health Sciences Center, Tucson, AZ. Seventeen (21\%) had seizures during follow-up ranging from 1.3 to 16 years. Fourteen (17\%) had epilepsy and 5 had seizures controlled by anticonvulsant drugs. CNS pathology in addition to the shunted hydrocephalus included encephalomalacia in 7, cerebral malformations in 2, and calcifications in 1. (Talwar D et al. Epilepsy in children with meningomyelocele. Pediatr Neurol July/August 1995;13:29-32). (Respond: Dr Talwar, Department of Pediatrics, University of Arizona Health Sciences Center, 1501 North Campbell Avenue, Tucson AZ 85724).

COMMENT. Although epilepsy in children with meningomyelocele occurs mainly in those with shunted hydrocephalus, structural cerebral abnormalities other than the shunt may be important causes.

\section{INFECTIOUS DISORDERS}

\section{HERPESVIRUS-6 INFECTION AND FIRST FEBRILE SEIZURES}

The association between acute human herpesvirus-6 (HHV-6) infection and first febrile convulsions was investigated prospectively in 42 children evaluated by virologic and serologic methods at the North Shore University Hospital-Cornell University Medical College, Manhasset, New York. Primary HHV-6 infection was documented by viral culture in $8(19 \%)$, and fourfold rises in HHV-6 titer were present in $9(26 \%)$ of 34 children whose blood was analyzed for acute and convalescent HHV- 6 titers. The majority (10 of 11 ) HHV6 cases were less than 24 months of age, and $3 / 11$ had roseola. Viral isolation in CSF, attempted in 29, including 7 with evidence of HHV-6 illness, was negative. (Barone SR et al. Human herpesvirus- 6 infection in children with first febrile seizures. I Pediatr July 1995;127:95-97). (Reprints: Stephen R Barone MD, North Shore University Hospital, 300 Community Drive, Manhasset, NY 11030).

COMMENT. Acute HHV-6 infection is a significant factor in the etiology of fever and convulsions in young children. Seizures associated with exanthem subitum and HHV-6 infection are not always simple in type, however. They are occasionally prolonged and complex and a manifestation of encephalitis or encephalopathy. See Progress in Pediatric Neurology II, 1994, Chicago, PNB Publishers, for a report and comment on HHV-6 infection, exanthem subitum, and encephalitis/encephalopathy. HHV-6 virus DNA was detected in the cerebrospinal fluid of 6 infants with exanthem subitum, 3 having a pleocytosis and elevated protein in the CSF. (Suga S et al. Ann Neurol 1993;33:597-603).

\section{OPSOCLONUS-MYOCLONUS OUTCOME}

The developmental outcome of 11 patients with opsoclonus-myoclonus, 8 having occult neuroblastoma, is reported from the Division of Pediatric Neurology, Children's Memorial Hospital, Chicago. Nine were treated with ACTH and 3 received prednisone. Symptoms recurred in 9 when ACTH was withdrawn. The response to predisone was minimal. Symptoms were not improved by removal of a neuroblastoma. The median age at presentation was 17 months. Follow-up ranged from 12 to 115 months. Delayed development with motor incoordination and speech delay occurred in 8 children and 3 had behavioral problems. IQs ranged from 56 to 75 in 7 children and one had a 